\section{OP0211-PARE WHO CARES? AN INVESTIGATION OF THE HEALTH AND PERCEIVED SOCIAL CARE NEEDS OF PEOPLE WITH RHEUMATOID ARTHRITIS LIVING IN SCOTLAND}

C. O'Neill ${ }^{1}$, A. Bosworth ${ }^{2}$, K.R. Martin ${ }^{3} .{ }^{1}$ Policy \& Public Affairs; ${ }^{2}$ CEO, National Rheumatoid Arthritis Society, Maidenhead; ${ }^{3}$ Epidemiology, University of Aberdeen, Aberdeen, United Kingdom

Background: Effective and sufficient levels of care and support for individuals newly diagnosed and those with established Rheumatoid Arthritis (RA) are needed to ensure optimal physical and mental health, as well as health-related quality of life. The aim of this study was to explore the extent of care needs among individuals with RA living in Scotland, UK and the factors that contribute to them, such as co-morbidities, perceived caregiver burden and complex care needs. Objectives: To establish whether the health and social care needs of people with RA in Scotland were being met, if there was regional variation and what other factors impacted such as wealth and age.

Methods: A cross-sectional study of individuals with RA who responded to an online survey (available 11 Nov 2015 to 22 Jan 2016) who were aged $\geq 16$ years, lived in Scotland and reported they had received a clinical diagnosis of RA. Respondents were allowed to skip questions they wished not to answer; standardised instruments were used (e.g., the Self-administered Comorbidity Questionnaire and the Self-Perceived Burden Scale). Descriptive analyses of quantitative data and thematic analyses of free text responses were conducted. Results: Overall, 387 individuals participated. The majority were female, of White Scottish or White British background, 45-64 years, and lived in a household with $\geq 2$ people. The majority, $83 \%$, reported well established RA (diagnosis $\geq 2$ years ago) and at least one other comorbidity (78\%) - most commonly depression $(30 \%)$. The average number of medications taken for RA was 3.2 (range $0-7$ ) and $30 \%$ reported taking 3 medications in total. Of those receiving care, the majority $(97 / 101)$ named family or friends/neighbours as caregivers and $76 \%(80 / 97)$ had an elevated level of self-perceived burden on their caregiver. Respondents who reported anxiety or depression had significantly higher average self-perceived burden scores when compared to those without, 33.0 versus 27.3 .

$89 \%$ responded that they did not know what types of circumstances might make them eligible for care and support from their local Council, and only 10\% reported receiving information about care and support from their local council. Very few $(n=40)$ had an assessment, with half being deemed eligible for support from their local council.

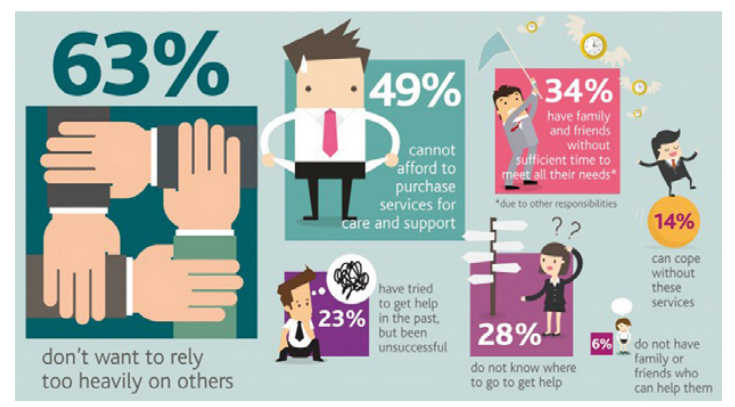

Conclusions: Survey responses suggest individuals with RA lack fundamental information about qualifying for and accessing formal resources and services provided by their local council. This is especially crucial for two reasons: 1) respondents indicated they do not want to rely heavily on others, like family or friends who are often the primary caregivers; 2 ) depression and anxiety are highly prevalent in this population. It is important to ensure those with RA do not have unmet needs at any stage, from being newly diagnosed to having established RA, so that they can flourish at home, at work and in their leisure time. Local councils should make access to information about help with formal social care easily accessible and ensure that health professionals know how best to sign-post people.

Acknowledgements: A partnership between the National Rheumatoid Arthritis Society (UK) and the University of Aberdeen

Disclosure of Interest: None declared

DOI: 10.1136/annrheumdis-2017-eular.1858

\section{THURSDAY, 15 JUNE 2017 \\ Macrophage M2 polarization: implications in fibrotizing diseases}

\section{OP0212 ENDOTHELIN-1 INDUCES A PROFIBROTIC PHENOTYPE IN CULTURED HUMAN MICROVASCULAR ENDOTHELIAL AND CIRCULATING MONOCYTE/MACROPHAGE CELLS}

S. Soldano $^{1}$, P. Montagna ${ }^{1}$, R. Brizzolara ${ }^{1}$, A.C. Trombetta ${ }^{1}$, A. Sulli ${ }^{1}$, C. Pizzorni ${ }^{1}$, M. Ghio ${ }^{1}$, S. Paolino ${ }^{1}$, V. Smith ${ }^{2}$, M. Cutolo ${ }^{1} .{ }^{1}$ Research Laboratory and Academic Division of Clinical Rheumatology, Department of
Internal Medicine, University of Genoa, Genoa, Italy: ${ }^{2}$ Department of Rheumatology, Ghent University Hospital, Ghent, Belgium

Background: The alteration of microvascular endothelial cell (EC) functions and the presence of macrophages in the immune inflammatory infiltrate, followed by the transition of these cell types into a profibrotic phenotype, represent early and crucial pathological features of the fibrotic process in systemic sclerosis (SSc) (1). The alternatively activated macrophage subset $\mathrm{M} 2 \mathrm{a}$ was found in several diseases characterized by extensive fibrosis (1). M2a macrophages express specific phenotype markers, CD206 (mannose receptor), CD204 and CD163 (scavenger receptors) as well as profibrotic molecules, primarily transforming growth factor- $\beta 1$ (TGF $\beta 1$ ) (1). Endothelin-1 (ET1) and/or TGF $\beta 1$ are known to induce the transition of fibroblasts into profibrotic myofibroblasts, which are key mediators of fibrosis in SSc.

Objectives: To investigate the effects of ET1 in inducing a profibrotic phenotype in cultured human microvascular ECs (HMVECs) and macrophages.

Methods: HMVECs, at 3rd culture passage, were grown in endothelial cell medium (EGM2MV) and treated for 6 days with ET1 (100nM) or treated for $1 \mathrm{hr}$ with $\mathrm{ET} 1$ receptor antagonist $\left(\mathrm{ET}_{\mathrm{A} / \mathrm{B}} \mathrm{RA}\right.$, bosentan $\left.10 \mu \mathrm{M}\right)$ before stimulation with ET1.

Human monocytes were isolated from peripheral blood mononuclear cells of healthy subjects using a monocyte isolation kit. The cells were maintained in RPMI growth medium for $24 \mathrm{hrs}$ and then treated for 6 days with ET1 or treated for $1 \mathrm{hr}$ with bosentan before stimulation with ET1

Cultured HMVECs and monocytes maintained in EGM2MV and RPMI growth medium, respectively, were used as untreated cells. Gene and protein expression of profibrotic myofibroblast markers $-\alpha$-smooth muscle actin ( $\alpha$-SMA), fibroblast specific protein-1 (S100A4), type 1 collagen (COL1) and fibronectin (FN) - were evaluated by quantitative real time polymerase chain reaction (qRT-PCR), Western blotting (WB) and immunocytochemistry (ICC) in cultured HMVECs. Gene and protein expression of M2a phenotype markers (CD206, CD204, CD163) and TGF $\beta 1$ were investigated by qRT-PCR and WB in cultured human macrophages. Statistical analysis was carried out by Mann-Whitney non-parametric test.

Results: In cultured HMVECs, ET1 induced the significant upregulation of the gene expression of $\alpha$-SMA, S100A4 (myofibroblast markers), COL1 and $F N$, compared to untreated cells $(p<0.001 ; p<0.001 ; p<0.05 ; p<0.01)$. $E T_{A / B} R A$ significantly contrasted the ET1 mediated transition of HMVECs into a profibrotic phenotype ( $p<0.05$ for $\alpha$-SMA, COL1 and FN; $p<0.01$ for S100A4 vs. ET1-treated cells)

In cultured human macrophages, ET1 induced the significant overexpression of M2a markers ( $p<0.05$ for CD204 and CD163; $p<0.01$ for CD206) and TGF $\beta 1$ $(p<0.01)$ compared to untreated cells. $E T_{A / B} R A$ significantly contrasted the ET1mediated transition of cultured macrophages into profibrotic $\mathrm{M} 2 \mathrm{a}(\mathrm{p}<0.05$ vs ET1-treated cells, for all investigated proteins). Data were confirmed by WB and ICC on both cultured cell types.

Conclusions: ET1 seems to be involved in the early phases of the fibrotic process by inducing the transition of both cultured HMVECs and macrophages into a profibrotic phenotype, myofibroblast and $\mathrm{M} 2 \mathrm{a}$ respectively (observed in $\mathrm{SSc}$ ), a process which is apparently contrasted by $\mathrm{ET}_{\mathrm{A} / \mathrm{B}} \mathrm{RA}$ treatment.

References:

[1] Wynn TA et al. Immunity. 2016;44:450-62

Disclosure of Interest: S. Soldano: None declared, P. Montagna: None declared, R. Brizzolara: None declared, A. Trombetta: None declared, A. Sulli: None declared, C. Pizzorni: None declared, M. Ghio: None declared, S. Paolino: None declared, V. Smith: None declared, M. Cutolo Grant/research support from: Actelion

DOI: 10.1136/annrheumdis-2017-eular.4317

\section{OP0213 MACROPHAGES FROM A SCLERODERMA SUBGROUP WITH HIGHER SKIN SCORES EXPRESS ACTIVATION MARKERS AND INDUCE FIBROBLASTS IN CO-CULTURE}

J. King, D. Sleep, Y. Sohrabi, A. Tam, B.A. Abdi, D. Abraham, C. Denton, R. Stratton. Centre for Rheumatology and Connective Tissue Diseases, Royal Free Hospital, London, United Kingdom

Background: Scleroderma (SSc) is characterized by pathological fibrosis. The mechanisms by which fibrosis occurs in SSc are not fully understood.

Alternatively activated M2-like macrophages are associated with fibrosis and have been found to have an important role in pathological fibrosis in humans. Therefore, there is interest in elucidating their role in SSc. M2 macrophages express mannose receptor CD206 and are known to secrete a number of soluble factors to establish a pro-fibrotic milieu when present in damaged tissues.

Furthermore, we have shown adenosine tri-phosphate (ATP) concentration is increased in the skin of patients with SSc. Within the extra-cellular environment, ATP is a Damage-Associated Molecular Pattern (DAMP), binding the P2X class of purinergic receptors. Such mechanisms may contribute to SSc pathology. Objectives: In this study, we explore the relationship of macrophage CD206 and $\mathrm{P}_{2} \mathrm{X}_{7}$ expression to Rodnan Skin Score. The role of these cells in establishing fibrosis was also examined in vitro.

Methods: 17 SSc patients and 9 controls were consented and their skin score recorded. Macrophages were derived from peripheral blood mononuclear cells (PBMCs) and identified through CD14 expression by FACS. CD206 and P2X 